\title{
Informed or anxious: patient preferences for release of test results of increasing sensitivity on electronic patient portals
}

\author{
Bethany Bruno ${ }^{1,2}\left(\mathbb{D} \cdot\right.$ Scott Steele ${ }^{3} \cdot$ Justin Carbone ${ }^{3} \cdot$ Katherine Schneider $^{4} \cdot$ Lori Posk $^{5,6} \cdot$ Susannah L. Rose Re $^{2,7,8}$
}

Received: 31 July 2021 / Accepted: 20 November 2021 / Published online: 8 January 2022

(c) IUPESM and Springer-Verlag GmbH Germany, part of Springer Nature 2021

\begin{abstract}
Worldwide, governments and healthcare systems are moving towards increased transparency to improve care quality, increase patient engagement, and decrease costs. For example, the American 21st Century Cures Act Final Rule requires providers to grant patients access to their electronic medical record. Unfortunately, limited research guides release of test results to online patient portals, especially concerning emotionally sensitive information. To address this gap, we surveyed the largest patient sample published to date. This cross-sectional survey project was conducted by the Market Research \& Insights and Office of Patient Experience departments at a large academic medical center. Data were analyzed in SPSS using descriptive statistics and Z-tests. Of 8030 respondents, $74 \%$ and $57 \%$ accepted first learning their results online for cholesterol and strep throat tests, respectively. Most prefer in-person appointments for more serious tests detecting cancer (54\%) and fetal miscarriage (53\%). Excluding sexually transmitted disease (STD) testing, there are no clinically significant differences in preference between respondents previously diagnosed with the condition in question and respondents without such experience. When weighing the possibility of a 3-week wait to hear from their provider, most patients want automatic release of cholesterol (94\%), strep throat (90\%), genetic (68\%), and STD (60\%) test results, but the majority say it is unacceptable to receive Alzheimer's (52\%), fetal miscarriage (51\%), and cancer (59\%) test results this way. Electronic results release is acceptable for less serious tests, but not for more consequential tests. Providers should consider patient preferences when developing policies to increase healthcare transparency.
\end{abstract}

Keywords Patient experience $\cdot$ Patient portal $\cdot$ Electronic medical record $\cdot$ Test results · Transparency

Bethany Bruno

bethany.anne.bruno@gmail.com

1 Department of Obstetrics \& Gynecology, Medical University of South Carolina, Charleston, SC 29425, USA

2 Cleveland Clinic Lerner College of Medicine of Case Western Reserve University, Cleveland, OH 44195, USA

3 Market Research, Cleveland Clinic, Cleveland, OH 44195, USA

4 Information Technology Division, Cleveland Clinic, Cleveland, OH 44195, USA

5 Department of Internal Medicine, Cleveland Clinic, Vero Beach, FL 32960, USA

6 Clinic Informatics, Cleveland Clinic, Vero Beach, FL 32960, USA

7 Office of Patient Experience, Cleveland Clinic, Cleveland, OH 44195, USA

8 Center for Bioethics, Cleveland Clinic, Cleveland, OH 44195, USA

\section{Introduction}

Worldwide, governments and healthcare systems are moving towards increased transparency in medicine [1, 2]. For example, the American $21^{\text {st }}$ Century Cures Act Final Rule requires that patients be able to access their electronic medical record with limited exceptions [3].

In sharing test results online, electronic patient portals seek to improve care quality, increase patient engagement, decrease healthcare costs, and ensure appropriate protection of personal health information. Proponents suggest that greater accessibility of results online will improve safety by decreasing the approximately $7 \%$ failure rate to inform patients of clinically significant outpatient test results [4-6]. Furthermore, electronic release of information provides an opportunity to return results to patients more quickly, even in real-time. Physicians report high levels of dissatisfaction with previous test result management systems [7]; new data suggests that the majority of doctors find releasing reports 
online useful, with unchanged or decreased follow-up emails, telephone calls, and office visits [8].

Nevertheless, limited research exists to guide which results should be shared, how, and when, particularly from patients' perspectives. In particular, concerns persist regarding release of abnormal results online, which may create patient anxiety and confusion given the need for expertise to interpret findings and the importance of further follow-up $[5,6]$. In fact, in a survey of approximately 1400 physicians, only one-fifth were comfortable with direct release of clinically significant abnormal results [9], and real cases document how unintended consequences of automatic release may lead to significant emotional distress [10,11]. Limited data suggest that results with high emotional impact should be communicated verbally first [12].

To inform this ongoing debate, this project surveyed the largest sample of patients to our knowledge to date for their thoughts, attitudes, and opinions surrounding the immediate release of test results to the electronic patient portal of a large academic medical center. Primary objectives included (1) to identify what methods were preferable, acceptable, and unacceptable to first receive results of increasingly serious tests, (2) to determine whether these preferences and acceptability change with a delay in receiving the results, and (3) to understand patients' emotional responses to the immediate release of test results.

\section{Methods}

An online survey was developed by the Cleveland Clinic Market Research \& Insights and Office of Patient Experience departments. The Market Research \& Insights department conducts both quantitative and qualitative projects to improve patient engagement and experience. Designed as a marketing project, this work was not considered human subjects research and was excluded from review by the Institutional Review Board in accordance with institutional and government policy. This approach allowed for ready access and quick patient responses to guide policy at our institution.

Incorporating both quantitative and qualitative questions, the survey asked respondents to identify which methods were preferable, acceptable, and unacceptable to first receive the results of increasingly serious tests (Online Resource 1). It also included logic to determine whether these preferences and acceptability change with a delay in receiving the results. Additional questions examined respondents' hypothetical emotional responses to the immediate release of increasingly serious test results before collecting demographic data.

The link to the online survey was provided in the electronic patient portal's quarterly newsletter that was sent out in November 2017, with fielding dates including November
22, 2017 through December 31, 2017. The newsletter was sent to all patients at Cleveland Clinic with an email address ( $\sim 1.5$ million). To participate, respondents needed to have an active portal account. Participants who completed the online survey were given the option to enter a sweepstakes to win one of five, \$50 Amazon eGift Cards. As of November 30,2017 , there were 881,777 active electronic patient portal users. There were 8030 respondents who reported having a portal account, and thus were eligible to participate $(<1 \%$ response among active portal users).

Data were analyzed in SPSS using descriptive statistics and Z-tests [13]. The Bonferroni method was used to correct for multiple comparisons. Two Market Research \& Insights team members independently reviewed qualitative data to identify themes. After this process of data immersion, the team members reconciled disagreement in their list of themes and selected representative comments for inclusion.

\section{Results}

Of the 8030 respondents, $71 \%$ identified as female, $85 \%$ white, and $54 \%$ between ages 55 and 74 (Table 1). One-third reported insurance through an employer plan $(32 \%)$ and an additional third reported insurance through Medicare either as a primary plan (22\%) or through a Medicare Advantage Plan (10\%). While one-third denied having any medical conditions (low risk, 32\%), 56\% reported having at least one medical condition (rising risk). Another 7\% reported having at least one medical condition as well as two or more emergency department or two or more inpatient admissions in the last 6 months (high risk). A majority of respondents reported having been tested for high cholesterol (88\%) and strep throat $(65 \%)$, with $51 \%$ and $39 \%$ of respondents reporting having tested positive, respectively. Sixteen percent (16\%) reported having received test results consistent with cancer and $<5 \%$ for STD, fetus miscarriage, genetic predisposition to cancer, and Alzheimer's disease on PET scan.

A majority of respondents were accepting of first learning their test results from the electronic patient portal for a cholesterol test (74\%, versus $62 \%$ prefer) and a strep throat test (57\%, versus $39 \%$ prefer) (Table 2). However, most respondents would prefer an in-person appointment for more serious tests such as a cancer test (54\%) and a test to determine if a woman will miscarry a fetus (53\%). Respondents who reported accessing the portal more than once a week were more accepting of receiving serious test results through the portal test results section than respondents who reported accessing the portal once a week to once a month (Alzheimer's: $30 \%$ vs. $23 \%, p<0.001$; cancer: $24 \%$ vs. $17 \%, p<0.001$ ), 1 to 11 times per year (Alzheimer's: $30 \%$ vs. $18 \%, p<0.001$; cancer: $24 \%$ vs. $14 \%$, $p<0.001$ ), or less than once a year/never (Alzheimer's: 
Table 1 Respondent Characteristics $(n=8,030)$

\begin{tabular}{|c|c|c|c|c|}
\hline & & $\mathbf{N}(\%)$ & & $\mathbf{N}(\%)$ \\
\hline Gender & & & Retired & \\
\hline Female & & $5726(71)$ & Yes & $3333(42)$ \\
\hline Age & & & Income & \\
\hline$<18$ & & $4(<1)$ & $<25,000$ & $779(10)$ \\
\hline $18-24$ & & $244(3)$ & $\$ 25,000-49,999$ & $1358(17)$ \\
\hline $25-34$ & & $684(9)$ & $\$ 50,000-74,499$ & $1272(16)$ \\
\hline $35-44$ & & $788(10)$ & $\$ 75,000-99,999$ & $943(12)$ \\
\hline $45-54$ & & $1274(16)$ & $\$ 100,000-124,999$ & $728(9)$ \\
\hline $55-64$ & & $2174(27)$ & $\$ 125,000-150,000$ & $395(5)$ \\
\hline $65-74$ & & $2150(27)$ & $>\$ 150,000$ & $563(7)$ \\
\hline $75-84$ & & $651(8)$ & Would rather not say & $1992(25)$ \\
\hline $85+$ & & $61(1)$ & & \\
\hline Race/Ethnicity & & & Education & \\
\hline White & & $6792(85)$ & HS Grad or less & $1011(13)$ \\
\hline Black or African American & & $532(7)$ & Some college, no degree & $1874(23)$ \\
\hline Hispanic & & $234(3)$ & Associate degree & $966(12)$ \\
\hline Asian & & $125(2)$ & Bachelor's degree & $2221(28)$ \\
\hline American Indian / Alaskan Native & & $47(1)$ & Master's degree & $1411(18)$ \\
\hline Hawaiian / Other Pacific Islander & & $9(<1)$ & Professional/doctorate degree & $547(7)$ \\
\hline Other & & $93(1)$ & & \\
\hline Prefer not to say & & $329(4)$ & & \\
\hline Medical Conditions & & & Insurance & \\
\hline Hypertension & $2748(34)$ & & Employer insurance plan & $2593(32)$ \\
\hline Hypercholesterolemia & $2722(34)$ & & Medicare as primary plan & $1800(22)$ \\
\hline Obesity & $1653(21)$ & & Spouse's insurance plan & $1206(15)$ \\
\hline Diabetes & $976(12)$ & & Medicare Advantage Plan & $778(10)$ \\
\hline Asthma & $813(10)$ & & Retirement Plan by Former Employer & $389(5)$ \\
\hline Coronary artery disease & $458(6)$ & & Medicaid & $344(4)$ \\
\hline $\begin{array}{l}\text { Chronic obstructive pulmonary } \\
\text { disease }\end{array}$ & $323(4)$ & & $\begin{array}{l}\text { Insurance purchased from insurance company/ } \\
\text { broker }\end{array}$ & $174(2)$ \\
\hline Chronic kidney disease & $274(3)$ & & Insurance purchased from insurance marketplace & $153(2)$ \\
\hline Heart failure & $245(3)$ & & Managed Medicaid plan & $101(1)$ \\
\hline Pneumonia & $89(1)$ & & Military Health Care Plan & $56(1)$ \\
\hline Prefer not to say & $414(5)$ & & Other & $274(3)$ \\
\hline \multirow[t]{2}{*}{ None } & $2648(33)$ & & I am not sure & $79(1)$ \\
\hline & & & No current health insurance & $83(1)$ \\
\hline Medical Risk Level $^{\text {a }}$ & & & Prescription Medications (in the past month) & \\
\hline Unknown & & $429(5)$ & None & \\
\hline Low Risk & & $2581(32)$ & $1-3$ & $1081(13)$ \\
\hline Rising Risk & & $4491(56)$ & 4-6 & $3622(45)$ \\
\hline \multirow[t]{5}{*}{ High Risk } & & $529(7)$ & $7-9$ & $2064(26)$ \\
\hline & & & $10+$ & $698(9)$ \\
\hline & & & Not sure & $369(5)$ \\
\hline & & & Prefer not to say & $21(<1)$ \\
\hline & & & & $175(2)$ \\
\hline Previous Medical Testing ${ }^{\mathbf{b}}$ & & & Portal Usage & \\
\hline Cholesterol Test & & & Daily & $147(2)$ \\
\hline Strep Throat Test & & $88(51)$ & 2-6 times a week & $729(9)$ \\
\hline Cancer Test & & $65(39)$ & Weekly & $1053(13)$ \\
\hline
\end{tabular}


Table 1 (continued)

\begin{tabular}{llll}
\hline & N $(\%)$ & N (\%) \\
\hline Gender & & Retired & $1905(24)$ \\
STD Testing & $36(16)$ & $2-3$ times a month & $1431(18)$ \\
Fetus Miscarriage $^{c}$ & $24(2)$ & Once a month & $1189(15)$ \\
Genetic Testing for Cancer & $12(5)$ & $6-11$ times a year & $1231(15)$ \\
PET Scan for Alzheimer's & $8(2)$ & 2 to 5 times a year & $179(2)$ \\
None were positive / prefer not to say & $2(<1)$ & Once a year & $109(1)$ \\
I have not undergone any of these tests & $(23)$ & $<$ Once a year & $57(1)$ \\
& 4 & Never & \\
\hline
\end{tabular}

${ }^{\mathrm{a}}$ Low risk $=$ no medical condition, rising risk $=$ has at least one medical condition, high risk $=$ has at least one medical condition and have had $2+$ emergency department or $2+$ inpatient experiences in the last 6 months

${ }^{\mathrm{b}}$ Number outside parentheses represents percentage tested for the condition, number within parentheses represents the percentage of those tested who reported a positive test result

${ }^{c}$ Only asked to females under the age of 45

$30 \%$ vs. $15 \%, p<0.001$; cancer: $24 \%$ vs. $8 \%, p<0.001)$. Respondents with total annual household income under $\$ 50,000$ were also more accepting of receiving serious test results through the portal test results section than those with a total annual household income greater than or equal to $\$ 100,000$ (Alzheimer's: $26 \%$ vs. $18 \%, p<0.001$; cancer: $20 \%$ vs. $14 \%, p<0.001)$. The same was true for respondents who reported a high school education versus those with a bachelor's degree or higher (Alzheimer's: $31 \%$ vs. $19 \%, p<0.001$; cancer: $23 \%$ vs. $15 \%, p<0.001$; fetal miscarriage: $31 \%$ vs. $15 \%, p<0.001)$. The trend reversed when considering less serious tests; those with an annual income over $\$ 100,000$ were more accepting of receiving cholesterol and strep test results through the portal test results section than those making less than $\$ 50,000$ annually (cholesterol: $78 \%$ vs. $70 \%, p<0.001$; strep: $62 \%$ vs. $54 \%, p<0.001)$. For all tests except fetal miscarriage, those in the over $\$ 100,000$ annual income bracket were more accepting of receiving results in a virtual, or online, appointment with a provider (Alzheimer's: $19 \%$ vs. $12 \%$, $p<0.001$; cancer: $18 \%$ vs. $11 \%, \mathrm{p}=<0.001$; STD: $19 \%$ vs. $12 \%, p<0.001$; genetic testing: $23 \%$ vs. $15 \%, p<0.001$;
Table 2 Acceptable and Preferred Methods for First Learning Test Result

\begin{tabular}{|c|c|c|c|c|c|c|}
\hline $\mathrm{n}=8030$ & $\begin{array}{l}\text { Provider } \\
\text { Phone Call }\end{array}$ & $\begin{array}{l}\text { In-Person } \\
\text { Appt. }\end{array}$ & $\begin{array}{l}\text { Portal Test } \\
\text { Results }\end{array}$ & $\begin{array}{l}\text { Portal } \\
\text { Message }\end{array}$ & $\begin{array}{l}\text { Virtual } \\
\text { Appt. }\end{array}$ & $\begin{array}{l}\text { Other } \\
\text { Way }^{\mathrm{c}}\end{array}$ \\
\hline Cholesterol Test & $\begin{array}{l}2031(25) / \\
677(8)^{\mathrm{a}}\end{array}$ & $\begin{array}{l}1329(17) / \\
201(3)\end{array}$ & $\begin{array}{l}5900(73) / \\
4961(\mathbf{6 2})\end{array}$ & $\begin{array}{l}3722(46) / \\
2062(\mathbf{2 6})\end{array}$ & $\begin{array}{l}1065(13) \\
/ 108(1)\end{array}$ & $\begin{array}{l}173(2) / \\
21(<\mathbf{1})\end{array}$ \\
\hline $\begin{array}{l}\text { Strep Throat } \\
\text { Test }\end{array}$ & $\begin{array}{l}3449(43) / \\
2167(27)\end{array}$ & $\begin{array}{l}1501(19) / \\
371(\mathbf{5})\end{array}$ & $\begin{array}{l}4606(57) / \\
3162(39)\end{array}$ & $\begin{array}{l}3697(46) / \\
2133(27)\end{array}$ & $\begin{array}{l}1199(15) \\
/ 166(2)\end{array}$ & $\begin{array}{l}166(2) / \\
31(<1)\end{array}$ \\
\hline $\begin{array}{l}\text { Genetic Testing } \\
\text { for Cancer }\end{array}$ & $\begin{array}{l}3018(38) / \\
1688(\mathbf{2 1})\end{array}$ & $\begin{array}{l}3497(44) / \\
2294(29)\end{array}$ & $\begin{array}{l}3201(40) / \\
1986(\mathbf{2 5})\end{array}$ & $\begin{array}{l}2829(35) / \\
1645(\mathbf{2 0})\end{array}$ & $\begin{array}{l}1375(17) \\
/ 381(5)\end{array}$ & $\begin{array}{l}145(2) \\
36(<1)\end{array}$ \\
\hline STD Testing & $\begin{array}{l}3598(45) / \\
2488(\mathbf{3 1})\end{array}$ & $\begin{array}{l}3859(48) / \\
2748(\mathbf{3 4})\end{array}$ & $\begin{array}{l}2303(29) / \\
1368(17)\end{array}$ & $\begin{array}{l}2000(25) / \\
1082(\mathbf{1 3})\end{array}$ & $\begin{array}{l}1152(14) \\
/ 284(4)\end{array}$ & $\begin{array}{l}148(2) / \\
60(1)\end{array}$ \\
\hline $\begin{array}{l}\text { PET Scan for } \\
\text { Alzheimer's }\end{array}$ & $\begin{array}{l}3395(42) / \\
2176(27)\end{array}$ & $\begin{array}{l}4765(59) / \\
3921(49)\end{array}$ & $\begin{array}{l}1743(22) / \\
836(\mathbf{1 0 )}\end{array}$ & $\begin{array}{l}1626(20) / \\
778(10)\end{array}$ & $\begin{array}{l}1136(14) \\
/ 286(4)\end{array}$ & $\begin{array}{l}110(1) / \\
33(<\mathbf{1})\end{array}$ \\
\hline $\begin{array}{l}\text { Fetus Miscarriage }{ }^{\mathbf{b}} \\
\mathrm{n}=1432\end{array}$ & $\begin{array}{l}770(54) / \\
429(30)\end{array}$ & $\begin{array}{l}1005(70) / \\
762(\mathbf{5 3})\end{array}$ & $\begin{array}{l}263(18) / \\
109(\mathbf{8})\end{array}$ & $\begin{array}{l}244(17) / \\
78(5)\end{array}$ & $\begin{array}{l}300(21) / \\
49(3)\end{array}$ & $\begin{array}{l}20(1) / \\
5(<\mathbf{1})\end{array}$ \\
\hline Cancer Test & $\begin{array}{l}3485(43) / \\
2310(29)\end{array}$ & $\begin{array}{l}5117(64) / \\
4316(54)\end{array}$ & $\begin{array}{l}1337(17) / \\
594(7)\end{array}$ & $\begin{array}{l}1302(16) / \\
550(7)\end{array}$ & $\begin{array}{l}1060(13) \\
/ 237(3)\end{array}$ & $\begin{array}{l}83(1) / \\
23(<\mathbf{1})\end{array}$ \\
\hline
\end{tabular}

${ }^{a}$ Acceptable n (\%) / Prefer n (\%)

${ }^{\mathrm{b}}$ Fetal miscarriage only asked to females under age 45

${ }^{c}$ Most common "other" ways: email, text message, mail, in-person 
cholesterol $18 \%$ vs. $12 \%, p<0.001$; strep: $19 \%$ vs. $13 \%$, $p<0.001)$. Again, a similar pattern existed when comparing individuals with a bachelor's degree or higher to those with a high school education or less (Alzheimer's: $16 \%$ vs. $10 \%, p<0.001$; cancer: $15 \%$ vs. $10 \%, p<0.001$; STD: $17 \%$ vs. $9 \%, p<0.001$; genetic testing: $21 \%$ vs. $11 \%$, $p<0.001$; cholesterol: $16 \%$ vs. $9 \%, p<0.001$, strep: $18 \%$ vs. $9 \%, p<0.001)$.

For most tests there are no notable differences in preference of receiving test results through the portal test results section between respondents who reported having previously been diagnosed with the condition in question ("patients") and respondents who reported having not ("non-patients") (Table 3). One significant exception is that patients were more likely than non-patients to be accepting of first learning their test results through the portal for a STD test (36\% vs. $28 \%, p=0.026)$. Although there were also statistically significant differences between self-identified patients and non-patients for both cancer ( $19 \%$ vs. $16 \%, \mathrm{p}=0.012)$ and cholesterol $(73 \%$ vs. $75 \%, p=0.010)$ testing, the magnitude of these differences was limited.

When patients have to wait two days to discuss their results with the physician or other healthcare provider's office, the overwhelming majority of respondents want cholesterol and strep throat tests immediately through the portal test results section, with a narrow majority also wanting results from genetic testing for cancer (Table 4). When weighing the possibility of a 3-week wait, most respondents want automatic portal results for cholesterol, strep throat, genetic, and STD tests, but a little over half still reported that it is unacceptable to receive Alzheimer's, fetal miscarriage, and cancer test results in this manner. Free response answers as to why this manner of returning results is unacceptable revealed two distinct themes: 1) the emotional impact of receiving test results, and 2) the need for explanation and follow-up with their healthcare provider. Respondents highlighted that in these sensitive situations, results from a computer are impersonal and do not provide an opportunity for clarification, questions, and discussion of next steps.

In the event of the immediate release of test results to the electronic patient portal, most respondents (51\%) would view these results, regardless of the test, prior to having the opportunity to discuss them with their provider. However, $41 \%$ of respondents would wait to discuss it first with their provider for a cancer test, $34 \%$ for a PET scan for Alzheimer's, and $30 \%$ for a test to determine if they would miscarry a fetus. Respondents reported they were more likely to feel informed with immediate results release when receiving less serious tests such as cholesterol and strep, but anxious when receiving more serious test results such as a fetal miscarriage (Table 5). Women were more likely than men to feel anxious with immediate results release after Alzheimer's ( $47 \%$ vs. $38 \%, p<0.001)$, cancer ( $53 \%$ vs. $43 \%$, $p<0.001)$, genetic ( $31 \%$ vs. $23 \%, p<0.001)$, and STD (38\% vs. $29 \%, p<0.001)$ testing. Meanwhile, men were more likely to feel indifferent about immediate results release for all tests (Alzheimer's: $7 \%$ vs. $4 \%, p<0.001$; cancer: $5 \%$ vs $3 \%, p<0.001$; cholesterol: $16 \%$ vs. $13 \%, \mathrm{p}=0.006$; genetic: $9 \%$ vs. $6 \%, \mathrm{p}=<0.001$; STD: $8 \%$ vs. $5 \%, p<0.001$; strep: $12 \%$ vs. $8 \%, p<0.001)$.
Table 3 Patients (Who Tested Positive) vs. Non-Patients: Acceptable / Preferred for First Learning Test Result Through Portal Test Results Section

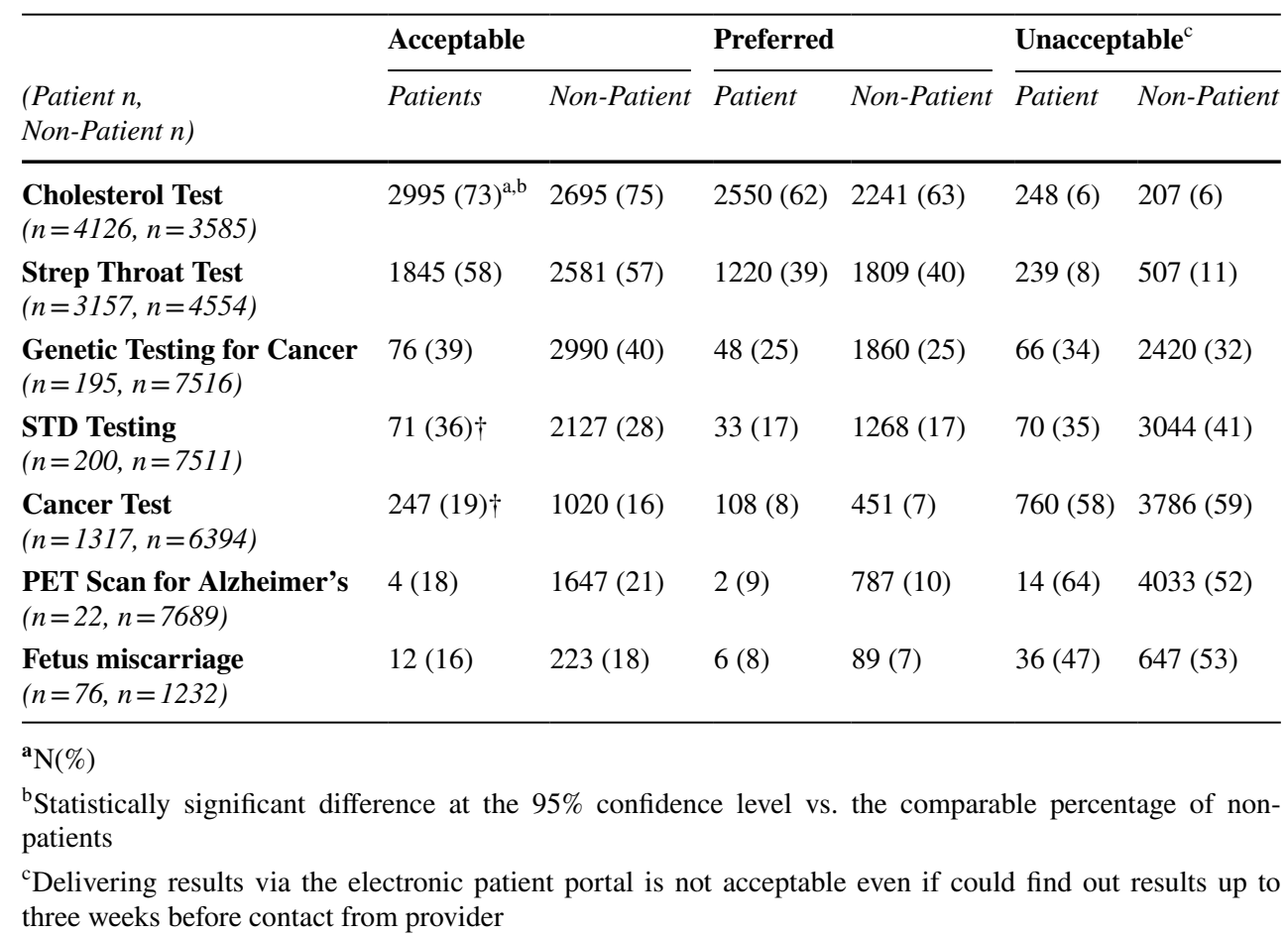


Table 4 Participants Who Initially Said Unacceptable to Learn Results through Portal Test Results Section: Acceptable if Can Find Out Results 2 Days, 1 Week, or 3 Weeks before Contact from Provider

\begin{tabular}{|l|l|l|l|l|}
\hline $\mathrm{n}=8030$ & 2 Days $^{\mathbf{a}}$ & $\mathbf{1 ~ W e e k ~}^{\mathbf{a}}$ & $\mathbf{3 ~ W e e k s ~}^{\mathbf{a}}$ & Not Acceptable $^{\mathbf{b}}$ \\
\hline Cholesterol Test & $7171(89)^{\mathbf{c}}$ & $7437(93)$ & $7545(94)$ & $485(6)$ \\
\hline Strep Throat Test & $6528(81)$ & $7016(87)$ & $7246(90)$ & $784(10)$ \\
\hline $\begin{array}{l}\text { Genetic Testing for } \\
\text { Cancer }\end{array}$ & $4454(55)$ & $5021(63)$ & $5452(68)$ & $2578(32)$ \\
\hline STD Testing & $3553(44)$ & $4179(52)$ & $4802(60)$ & $3228(40)$ \\
\hline $\begin{array}{l}\text { PET Scan for } \\
\text { Alzheimer's }\end{array}$ & $2671(33)$ & $3227(40)$ & $3846(48)$ & $4184(52)$ \\
\hline $\begin{array}{l}\text { Fetus Miscarriage } \\
\mathrm{n}=1432\end{array}$ & $410(29)$ & $509(36)$ & $698(49)$ & $734(51)$ \\
\hline Cancer Test & $2137(27)$ & $2648(33)$ & $3321(41)$ & $4709(59)$ \\
\hline
\end{tabular}

aPercent who said: "In this scenario it is acceptable to first learn this test result through the electronic patient portal."

${ }^{b}$ Delivering results via the electronic patient portal is not acceptable in any of these scenarios

${ }^{\mathrm{c}} \mathrm{N}(\%)$

With regard to respondents' prior experiences, of those who reported testing positive for high cholesterol, $68 \%$ received the test results through the electronic patient portal prior to discussing the results with their physician / provider's office. Twenty-two percent (22\%) of those who tested positive for a STD, $18 \%$ of those who had a PET scan consistent with Alzheimer's, and $18 \%$ of those who tested positive for strep throat received their results through the portal prior to discussing the results with their physician / provider's office (vs. $17 \%$ genetic testing for cancer, $16 \%$ cancer test, and $13 \%$ fetal miscarriage). For less serious tests such as strep and cholesterol, patients generally felt more indifferent or positive towards receiving results through the portal. Representative quotes include:

- "Because strep throat is a common and non-life-threatening illness, I was glad to receive the results as soon as possible via [the portal]." (Strep)
Table 5 Emotions Associated with Immediate Portal Results Release

\begin{tabular}{|l|l|l|l|l|l|l|l|l|}
\hline $\mathrm{n}=8030$ & Informed & Glad & Relieved & Anxious & Angry & Annoyed & Indifferent $^{\text {Other }}{ }^{\mathrm{b}}$ \\
\hline $\begin{array}{l}\text { Cholesterol } \\
\text { Test }\end{array}$ & $\begin{array}{l}4959 \\
(62)^{\mathrm{a}}\end{array}$ & $\begin{array}{l}1718 \\
(21)\end{array}$ & $963(12)$ & $254(3)$ & $\begin{array}{l}40 \\
(<1)\end{array}$ & $80(1)$ & $1113(14)$ & $121(2)$ \\
\hline $\begin{array}{l}\text { Strep Throat } \\
\text { Test }\end{array}$ & $4590(57)$ & $\begin{array}{l}2012 \\
(25)\end{array}$ & $\begin{array}{l}1489 \\
(19)\end{array}$ & $339(4)$ & $66(1)$ & $122(2)$ & $753(9)$ & $115(1)$ \\
\hline $\begin{array}{l}\text { Genetic } \\
\text { Testing for } \\
\text { Cancer }\end{array}$ & $4056(51)$ & $\begin{array}{l}845 \\
(11)\end{array}$ & $871(11)$ & $\begin{array}{l}2286 \\
(28)\end{array}$ & $\begin{array}{l}382 \\
(5)\end{array}$ & $362(5)$ & $532(7)$ & $197(2)$ \\
\hline STD Testing & $3199(40)$ & $\begin{array}{l}723 \\
(9)\end{array}$ & $885(11)$ & $\begin{array}{l}2820 \\
(35)\end{array}$ & $\begin{array}{l}840 \\
(10)\end{array}$ & $533(7)$ & $443(6)$ & $300(4)$ \\
\hline $\begin{array}{l}\text { PET Scan for } \\
\text { Alzheimer's }\end{array}$ & $2911(36)$ & $\begin{array}{l}572 \\
(7)\end{array}$ & $734(9)$ & $\begin{array}{l}3550 \\
(44)\end{array}$ & $\begin{array}{l}765 \\
(10)\end{array}$ & $525(7)$ & $379(5)$ & $276(3)$ \\
\hline $\begin{array}{l}\text { Fetus } \\
\text { Miscarriage } \\
\mathrm{n}=1432\end{array}$ & $507(35)$ & $\begin{array}{l}100 \\
(7)\end{array}$ & $155(11)$ & $735(51)$ & $\begin{array}{l}221 \\
(15)\end{array}$ & $115(8)$ & $86(6)$ & $75(5)$ \\
\hline Cancer Test & $2437(30)$ & $\begin{array}{l}514 \\
(6)\end{array}$ & $717(9)$ & $\begin{array}{l}4040 \\
(50)\end{array}$ & $\begin{array}{l}1143 \\
(14)\end{array}$ & $599(7)$ & $257(3)$ & $315(4)$ \\
\hline
\end{tabular}

${ }^{\mathrm{a}} \mathrm{N}(\%)$

${ }^{\mathrm{b}}$ Common responses included confused, scared, sad, concerned, and frustrated 
- " $[\mathrm{I}]$ appreciated learning before [my doctor] appointment. [I was] better prepared to discuss [the] result." (Cholesterol)

For patients with cancer, emotions were more mixed; some were glad to be informed, but others felt anxious and had questions. Representative quotes include:

- "[I felt] informed and relieved that I would have time to do... research so I could ask the oncologist... specific... questions." (Cancer)

- " $[\mathrm{I} \mathrm{had}]$ so many questions [that] I wanted answered right then... but [there was] no one to ask, so I worried more." (Cancer)

- "I am fine with knowing. Waiting for results makes me more anxious then finding out and knowing." (Cancer)

- "[I was] upset and shock[ed]. [The] test reported [a] possibility of metastatic disease. I was referred for [the] scan on minor follow-up, so it was very upsetting. My doctor did try to contact me prior to [the] report being released." (Cancer)

\section{Discussion}

Recognizing the trend towards increased transparency in healthcare worldwide [1,2], we conducted this survey project to learn more about patients' preferences for use of electronic patient portals. We found that release of results online is an acceptable way to deliver news for less serious tests, but not for more consequential tests, because of the personal nature of the results, the need for immediate answers to questions, and the desire for interpretation and follow-up planning. This pattern largely remained even when considering up to a three-week wait time to receive results directly from the provider. In this vein, our findings suggest that patients are more likely to feel informed when receiving less serious test results, but more anxious when receiving results from more consequential tests. These results are especially important given that the American $21^{\text {st }}$ Century Cures Act Final Rule now requires that patients be able to access their electronic medical record with limited exceptions [3].

Our findings build upon previous literature on patient preferences for online portals [14]. Although feedback has been largely positive in some studies [15], notable cases document how automatic release of abnormal results may lead to significant emotional distress [10 11]. Even normal results may lead to confusion and stress for patients, given potential difficulty with interpreting complex medical terminology [16]. Qualitative comments from patients in our large-scale survey echo these sentiments. For example, previous qualitative analysis of $13 \mathrm{semi}$-structured interviews suggested that results with high emotional impact should be communicated verbally first [12]. Furthermore, patients' desire to receive more serious results directly from providers and anxiety about these tests reflect previously documented physician concerns regarding electronic release of abnormal results $[6,9]$.

To our knowledge, this is the largest sample of patients surveyed to date on immediate release of test results online. The project is also strengthened by inclusion of patients who have tested positive on the tests included in the survey; these real-life experiences inform their preferences, and the similarity in findings between patients and non-patients who have never tested positive supports the validity of even this more hypothetical data.

Nevertheless, this project has several limitations. First, our response rate was low at $<1 \%$. This may introduce bias, as patients who feel strongly about the issue might have been more likely to participate and may be fundamentally different than others who use the electronic patient portal. However, this project was conducted using market research techniques, not biomedical research methods, and in marketing, low response rates along this magnitude are not atypical [17]. Furthermore, in the recent past there has been a shift towards recognizing that a higher response rate does not ensure a more representative sample [18-20].

Table 6 Recommendations to Guide Utilization of Electronic Patient Portals for Test Results Release

\section{Recommendations}

Recognizing our finding that the large majority of patients prefer immediate release of less sensitive test results, healthcare organizations should automatically release results of less sensitive tests to electronic patient portals.

Recognizing our finding that many patients prefer to hear the results of more sensitive tests directly from their provider, healthcare organizations should consider a temporary delay in the automatic release of more sensitive test results to electronic patient portals. This delay may be automatically triggered or an option selected by the clinician after discussion with the patient at the time of ordering.

Given the wide variability of patient preferences in our findings, electronic patient portals should include settings to accommodate different preferences. For example, technology should allow for patients to opt-out of immediate release of results and choose another alternative.

Acknowledging the potential for negative reactions to sensitive test results released prior to physician contact noted in our findings, at the time of ordering, providers should take care to discuss the significance of the results and the plans for their release. Providers should also indicate understanding of the potential emotional impact and remind patients that they may choose to wait to view the results in the portal until they speak with the provider. 
Our sample population was largely representative of the institution's patient population with regard to race, and although survey respondents were slightly younger with a greater proportion of women, this shift reflects patterns of online patient portal use previously documented in the literature [10]. Nevertheless, our findings may not be generalizable to other populations. Second, our findings rely exclusively on respondent recall, which introduces potential bias and inaccuracy. However, to maintain anonymity, it was important that respondents self-identified as electronic patient portal users and self-reported the frequency of their portal use, rather than second-hand collection of this data from digital health records. Similarly, respondents also self-identified as patients for the conditions in question.

Notably, our data was collected prior to the COVID-19 pandemic, which has led to a drastic increase in the use of virtual visits for health care. We found that a minority of respondents were accepting of virtual visits as an option for direct delivery of test results from their provider. Following documented trends in the literature [21], those of higher income and educational attainment demonstrated higher levels of support for telemedicine. Acceptance of virtual visits for return of test results may be substantially greater in a post-pandemic world.

Further research is needed to optimize the implementation of electronic patient portals and telehealth experiences more generally. As governments and healthcare systems develop new standards for transparency in medicine, data should guide which results should be shared on electronic patient portals, for whom, how, and when. In this time of growing distrust in science [22], research must not only examine the impact of such regulation on patients and providers, but also on society and medicine as a whole.

In conclusion, our findings suggest that release of results online is an acceptable way to deliver news for less serious tests, but not for more consequential tests. Although providing patients with access to test results increases transparency, it may not be appropriate in all circumstances. In this era of increasing transparency in medicine, we present evidence-based recommendations to help healthcare institutions and providers respond in a way that empowers and supports patients (Table 6). Moving forward, healthcare organizations should automatically release results of less sensitive tests to electronic patient portals but consider a temporary delay in the automatic release of more sensitive information. Electronic patient portals should not supersede traditional patient-provider communication, particularly with regard to potentially anxiety-provoking, sensitive test results that require immediate explanation and timely follow-up. Through preemptive conversations with patients regarding the significance of results and plans for their release, providers acknowledge the potential emotional impact of test results and may tailor care to accommodate different patient preferences.

Supplementary information The online version contains supplementary material available at https://doi.org/10.1007/s12553-021-00628-5.

Acknowledgements Internal peer review by MaryBeth Mercer, MPH.

Author contributions LP and SLR conceived the initial idea and BBreviewed the literature. SS and JC designed the survey, collected responses, and analyzed the data with contributions from all authors. BB wrote themanuscript with input from all authors. All authors approve the final versionof the manuscript as published.

Funding Internally funded by theCleveland Clinic MyChart Team.

Data Availability Data are available on requestfrom the authors.

\section{Declarations}

Ethical approval Designed as a marketing project, this work was not considered human subjects research and was excluded from review by the Institutional Review Board in accordance with institutional and government policy.

Conflict of interest The authors declare that they have no conflict of interest.

\section{References}

1. Feeley TW, Shine KI. Access to the medical record for patients and involved providers: Transparency through electronic tools. Ann. Intern. Med. American College of Physicians; 2011. p. 853-4.

2. Scheurer D. Hospitalists should embrace advances, transparency in health record technology [Internet]. Hospitalist. 2015 [cited 2020 Feb 12]. Available from: https://www.the-hospitalist.org/ hospitalist/article/122299/hospitalists-should-embrace-advancestransparency-health-record

3. Office of the National Coordinator for Health Information Technology. About ONC's Cures Act Final Rule [Internet]. [cited 2020 Nov 18]. Available from: https://www.healthit.gov/curesrule/ overview/about-oncs-cures-act-final-rule

4. Casalino MDO, Jerge KF, Frequency of failure to inform patients of clinically significant outpatient test results (Archives of Internal Medicine,. 169, 12, (1123-1129)). Arch Intern Med. 2009;2009(169):1626.

5. Giardina TD, Singh H. Should patients get direct access to their laboratory test results?: An answer with many questions. JAMA - J Am Med Assoc. 2011;306:2502-3.

6. Callen J, Giardina TD, Singh H, Li L, Paoloni R, Georgiou A, et al. Emergency physicians' views of direct notification of laboratory and radiology results to patients using the internet: A multisite survey. J Med Internet Res. 2015;17:1-13.

7. Poon EG, Gandhi TK, Sequist TD, Murff HJ, Karson AS, Bates DW. I Wish I Had Seen This Test Result Earlier! Arch Intern Med. 2004; 164:2223.

8. Henshaw D, Okawa G, Ching K, Garrido T, Qian H, Tsai J. Access to radiology reports via an online patient portal: Experiences of 
referring physicians and patients. J Am Coll Radiol [Internet]. Elsevier Inc; 2015;12:582-586.e1. Available from: https://doi.org/ 10.1016/j.jacr.2015.01.015

9. Giardina TD, Callen J, Georgiou A, Westbrook JI, Greisinger A, Esquivel A, et al. Releasing test results directly to patients: A multisite survey of physician perspectives. Patient Educ Couns [Internet]. Elsevier Ireland Ltd; 2015;98:788-96. Available from: https://doi.org/10.1016/j.pec.2015.02.011

10. Krasowski M, Grieme C, Cassady B, Dreyer N, Wanat K, Hightower $\mathrm{M}$, et al. Variation in results release and patient portal access to diagnostic test results at an academic medical center. J Pathol Inform [Internet]. Wolters Kluwer Medknow Publications; 2017 [cited 2020 Feb 12];8:45. Available from: http://www.ncbi.nlm.nih.gov/pubmed/ 29226008

11. Pillemer F, Price RA, Paone S, Martich GD, Albert S, Haidari $\mathrm{L}$, et al. Direct release of test results to patients increases patient engagement and utilization of care. PLoS ONE. 2016;11:1-9.

12. Giardina T, Modi V, Parrish D, Singh H. The patient portal and abnormal test results: An exploratory study of patient experiences. Patient Exp J. 2015;2:148-54.

13. IBM Corp. IBM SPSS Statistics for Windows. Armonk, NY: IBM Corp; 2020.

14. Kayastha N, Pollak KI, LeBlanc TW. Open Oncology Notes: A Qualitative Study of Oncology Patients' Experiences Reading Their Cancer Care Notes. American Society of Clinical Oncology; 2018;14:e251-8. https://doi.org/10.1200/JOP.2017.028605

15. Christensen K, Sue VM. Viewing Laboratory Test Results Online: Patients' Actions and Reactions. J Particip Med. 2013;5:e38.
16. Giardina TD, Baldwin J, Nystrom DT, Sittig DF, Singh H. Patient perceptions of receiving test results via online portals: A mixedmethods study. J Am Med Informatics Assoc. 2018;25:440-6.

17. Hulland J, Baumgartner H, Smith KM. Marketing survey research best practices: evidence and recommendations from a review of JAMS articles. J Acad Mark Sci; 2018;46:92-108.

18. Hendra R, Hill A. Rethinking Response Rates: New Evidence of Little Relationship Between Survey Response Rates and Nonresponse Bias. Eval Rev [Internet]. SAGE Publications Inc.; 2019 [cited 2020 Feb 15];43:307-30. Available from: http://www.ncbi. nlm.nih.gov/pubmed/30580577

19. Keeter S. The Impact of Survey Non-Response on Survey Accuracy. In: Vannette DL, Krosnick JA, editors. Palgrave Handb Surv Res. Cham, Switzerland: Springer International Publishing; 2018. p. 373-81.

20. Keeter S. Evidence about the Accuracy of Surveys in the Face of Declining Response Rates. In: Vannette D, Krosnick JA, editors. Palgrave Handb Surv Res. Cham, Switzerland: Springer International Publishing; 2018. p. 19-22.

21. Stenberg PL. Rural Individuals' Telehealth Practices: An Overview [Internet]. 2018. Available from: www.ers.usda.gov

22. Khullar D. Do You Trust the Medical Profession? - The New York Times. New York Times [Internet]. [cited 2021 Sep 26]; Available from: https://www.nytimes.com/2018/01/23/upshot/do-you-trustthe-medical-profession.html

Publisher's Note Springer Nature remains neutral with regard to jurisdictional claims in published maps and institutional affiliations. 